This accords well with the measurements of the concentration of radioactive materials in the atmosphere and in rain which have now been published by the Health Physics and Medical Division of the AERE, Harwell. The report (HMSO, 7s.), which runs up to the middle of 1967 , shows that the average concentration of strontium-90 in rainwater had decreased by roughly 40 per cent between the first half of 1966 and the first half of 1967 . Because rainfall in 1967 was considerably less than in the previous year, the actual deposition of strontium-90 in the first half of 1967 was only 40 per cent of that deposited in the same period during the preceding year. By the end of 1966 , it seems as if the rate of deposition of fresh strontium-90 had become comparable with and smaller than the rate of disappearance of deposited strontium-90 by means of radioactive decay, so that "for the first time", the "cumulative deposition began to decrease with" time". The balance was reversed with the spring rains in 1967, but it is clear that an end is in sight to the accumulation of radioactivity in the soil.

\section{All Quiet on the Quiet Sun}

Lrke a great actress in later life, the organization of the International Years of the Quiet Sun is now well settled in the habit of making its final appearance. Formally, it is true, the great symposium at Imperial College last July marked the end of the period of co-ordinated or at least simultaneous observation. Now there has appeared the latest issue of IQSY Notes, the twentyfirst, which is full of valedictory statements and which also contains the announcement that this issue will be the last. The next step is the publication of the Annals of the IQSY, which is being managed by the Royal Society. There will be admiration and even gratitude for the firm promise that the first of the eight or nine volumes in this series will appear early this year, and that publication of the whole series - which will include a record of the symposium last Julyshould be complete by the end of 1969. With luck, it should be possible to avoid overlap between the productions of the IQSY and of Dr Herbert Freeman's Commission on Solar and Terrestrial Physics, now in the process of gestation.

Although the latest IQSY Notes has no great surprises, it does provide some information about the financing of international operations like these. It is notable that the total cost of administering the IQSY for a period of $5 \frac{1}{2}$ years amounted to merely $\$ 173,000$ - a sum which had to cover the maintenance of the secretariat in London, the publication of manuals and the organization of meetings. The publication of the Annals is reckoned to cost a further $\$ 60,000$. Most of the funds have been raised by voluntary contributions from the national committees of participating countries. The statement of the council goes out of its way to emphasize that "the payment of a contribution has never been a condition of adherence to the IQSY programme. Contributing and non-contributing committees have been treated exactly alike. . . . This was essential, since the prime objective of the scientific programme was to encourage the widest possible geographical participation in the programme. . . ." This decision was no doubt wise, for the list of contributors suggests that some participants have been rather slow in paying up. It is perhaps understandable that Taiwan and the Congo should not have paid after the first year or two. It is more surprising that Belgium, Finland, Israel, Rumania and Switzerland should not have contributed after a similar period. The Soviet Union had only paid two contributions out of six by October last year-a total of $\$ 10,000$. Difficulties about the convertibility of the rouble (and of the rupee) are known to have been a complication in this connexion. But the IQSY seems to have managed well enough and, even if its scientific programme was inescapably a somewhat undramatic business, the organization may well have been able to establish standards of good management among international organizations.

\section{More Medical Science}

A sMaLL reform in the organization of the British Medical Association seems likely to come about as a result of suggestions made by Dr Ronald Gibson, chairman of the council of the association. Dr Gibson has proposed that all the scientific and educational work done by the BMA should be brought under the umbrella of a central board. As well as the work of the present Committee on Medical Science, the board would provide for scientific and sociological work. But the hope expressed by Dr Gibson that the BMA could in this way "prove its right to be considered a forceful entity in the field of medical science" is hardly realistic. The proposal does not recommend any increase in the money which the BMA spends on research-last year it was $£ 60,000$ - but simply concentrates on the reform of the committee structure. Nor is the suggestion particularly new-a similar idea was put forward some years ago. Dr Gibson has suggested that if the board is set up-a decision which the council of the BMA will have to take within the next few weeks-it might also sponsor some general sociological surveys. Topics put forward include drug addiction, the population explosion, nutrition, the stress diseases and the like.

There seems to be no reason why the council should not approve the suggestion, modest as it is. It may, however, put the BMA into a position where it could begin to influence medical research in Britain, given a greater financial outlay. A counterweight to the massive influence of the Medical Research Council would not be entirely unwelcome. The field where the BMA might be most influential, clinical research, has not so far had the same attention in the MRC as more basic studies, although this may change when the MRC Clinical Research Centre opens at Brent Hospital in 1970. In the BMA, the move reflects a feeling that the politics of medicine has in the past few years been allowed to obscure the more cerebral activities of the BMA. Having exhibited its taste and talent for political controversy, the argument runs, the BMA should now try to divorce itself somewhat from the image of a militant, if successful, trade union.

The American Medical Association itself turned to research for many of the same reasons several years ago. There was a feeling that the AMA had become too closely identified with the fight against the Medicare proposals, and too far detached from scientific research. But the move to support basic research, in the Institute for Biomedical Research at the AMA headquarters in Chicago, seems not to have been wholly successful. After only two years of existence, the institute is now 
to have its third director-George W. Beadle, the retiring president of the University of Chicago. (His predecessors were Dr Roy E. Ritts and Sir John Eccles.) The AMA has also decided to move the institute to a new site on the campus of the University of Chicago. Unless the BMA decides to spend a good deal more on research, however, it is unlikely to be troubled by problems such as these.

\section{Doctors' Complaints}

THE career structure of the medical profession in Britain is an important stimulus of the emigration of doctors and an effective deterrent to their return. This is one of the conclusions reached by an interview board sent by the Ministry of Health to the United States and Canada last Oetober and which has now reported its findings. (British Medical Journal, i, $45 ; 1968$.)

Between 1962 and 1964 the rate of emigration of British doctors to all countries was about 300 a yearmore than one-sixth of the annual output of British medical schools in those years. This rate of emigration, which there is no reason to suppose will have diminished in subsequent years, was the goad to the board's departure. Having advertised its coming in various medical journals, it was able to interview 135 out of the 200 doctors who applied to it, with the purpose both of finding them jobs in Britain and of ascertaining why they had left and what impediments they saw to their return. Fifty of the doctors whom the board interviewed have already been offered, and have accepted, appointments in Britain and it is expected that more will do so.

The board discovered a fairly consistent picture of dissatisfaction with the National Health Service and its doings. General practitioners who in Britain had aspired to a specialist career gave as their reason for emigrating the lack of hospital facilities for doing major surgery and other specialized practice, and the waiting period for senior posts after the appropriate higher qualifications had been gained. Other reasons for emigrating were the paucity of senior academic posts in the United Kingdom and the relative scarcity of research funds. To the board's regret, it found that an emigrant's decision to leave was not always a purely personal one: "evidence of British consultants and professors advising and encouraging trainees to emigrate because of the uncertainty of their prospects and the rigidity of the National Health Service and academic structure in the United Kingdom was unfortunately forthcoming".

For those who wish to return to the United Kingdom, the most formidable obstacle is the insistence by the National Health Service that candidates attend an interview. If unsuccessful the candidate is left with his travelling expenses to pay, and if successful he is faced with removal costs of his dependants and effects as well. In this instance the board was empowered to reimburse such costs, which may account for much of its success in attracting doctors back. Other impedi. ments to a return are the lack of information about jobs, the hostile attitude of the North American press, and its British element in particular, towards the National Health Service, and the lack of any accepted equivalence bctween the higher qualifications awarded in North America and in Britain.
One reason for the board's success may have been that it was less scrupulous in selecting candidates for interview than other interview boards have been. It recommends that the obstacles to return should be reduced, and that to diminish the rate of emigration in future the arrangements for career guidance of trainees should be improved and that more opportunities should be created for academic careers. The Minister of Health is now studying these recommendations.

The loss of 300 doctors a year is indeed serious, but should be seen in proportion to the numbers Britain gains from other countries. Last year almost 2,000 doctors from the Commonwealth alone applied to enter Britain. In 1965, the most recent year for which figures are available, there were 6,000 doctors working in National Health hospitals who had been born abroad-about 30 per cent of the total. Of general practitioners 2,600 , or 12 per cent of the total, were born abroad. If every doctor were to practise in the country of his birth, Britain would not be the gainer. But this is not to decry any efforts that the ministry may now make to encourage the return of expatriates, and to allay the discontent of those who would follow them.

\section{More on Asbestosis}

THAT there are risks associated with asbestos is not now disputed. A review of the problem as it occurs in Britain has just been published as a memorandum by the Advisory Panel on Problems Arising from the Use of Asbestos (HMSO, 3s. 9d.). The advisory panel, set up in 1965 by HM Factory Inspectorate, is responsible for considering the use of asbestos in relation to the health of those directly or indirectly exposed to asbestos in their occupations. Over the whole country the panel estimates that about 20,000 persons are exposed to asbestos in the use or handling of the fibres. The figure is probably higher than this; people can easily be put at risk by working near to where asbestos is handled. The present Asbestos Industry Regulations, 1931, are applied to some 300 registered factories, but the report says that there are many other factories which use asbestos products and which do not come within the regulations. The Ministry of Labour is at present drawing up new regulations to cover a wider range of factories.

It was in the 1920 s that it was first elearly recognized that asbestosis, a fibrotic condition of the lungs, is caused by occupational exposure to asbestos. Within a few years it was suggested that the disease might be complicated by the development of carcinoma of the lung, but an association was not generally accepted until the $1950 \mathrm{~s}$. Recently, there has been concern over the occurrence of mesothelial tumours of the pleura or peritoneum which appear to be causally related to asbestos exposure in many cases. Since 1966 mesothelioma has been a scheduled industrial discase.

The advisory panel concludes that there is an increasing incidence of asbestosis in the country. The most likely explanation for this increase is the greater use of asbestos and the greater numbers of people employed in the industry over the past 20 years. But the panel says that "there is no evidence that the overall attack rate has decreased in the industry over this period, although it has in some textile mills in which the dust conditions have been greatly 